\title{
Effect of a Pharmacist-Led Program on Improving Outcomes in Patients with Type 2 Diabetes Mellitus from Northern Cyprus: A Randomized Controlled Trial
}

\author{
Eylem Ilktac Korcegez, MSc, PhD Candidate; Mesut Sancar, PhD; and Kutay Demirkan, PharmD
}

\begin{abstract}
BACKGROUND: The management of type 2 diabetes mellitus is complex, requiring continuous medical care by health care professionals and considerable self-care efforts by patients. Pharmacist-led care programs have been shown to help patients with diabetes succeed in achieving treatment goals and improving outcomes. Pharmacist-led care is a new health care concept in Northern Cyprus.
\end{abstract}

OBJECTIVE: To evaluate the effect of a pharmacist-led care program on glycemic control, determined by hemoglobin A1c (A1C), and secondarily on blood pressure, lipid profile, body mass index (BMI), waist circumference, medication adherence, and self-care activities, for patients with type 2 diabetes over a 12-month period.

METHODS: This was a prospective, randomized controlled study conducted in a public hospital's outpatient diabetes clinic, with 152 patients who had been diagnosed with type 2 diabetes. Of these, 75 patients were in the intervention group, and 77 patients were in the usual care group. The intervention group participated in a pharmacist-led care program with a clinical pharmacist who provided 5 face-to-face educational sessions over a period of 12 months. The main outcome measure was change in A1c, and secondary outcome measures were changes in fasting blood glucose, systolic and diastolic blood pressure, lipid values (total cholesterol, low-density lipoprotein cholesterol [LDL-C], high-density lipoprotein cholesterol [HDL-C], and serum levels of triglycerides [TGs]), BMI, waist circumference, self-reported medication adherence (Morisky-Green test), and self-care activities. Changes in outcome measures from baseline to the end of the study were assessed using the Mann-Whitney U-test and Wilcoxon test.

RESULTS: At the end of the 12-month study period, the intervention patients showed a greater reduction in A1c values than the usual care patients $(-0.74 \%$ vs. $-0.04 \% ; P<0.001)$. Both groups showed significant reductions in fasting blood glucose levels between baseline and the end of 12 months; the difference between the groups was statistically nonsignificant $(P=0.410)$. When comparing the intervention and usual care groups, there was a significant decrease in systolic $(P=0.01)$ and diastolic blood pressure $(P=0.04)$ at the end of the trial. No significant differences were found between the groups in LDL-C, HDL-C, or TG values; however, total cholesterol levels did decrease significantly $(P=0.063,0.331,0.896$, and 0.04 , respectively). Significant reductions occurred in BMI $(P<0.001)$ and waist circumference $(P<0.001)$, and improvements were observed in self-reported medication adherence and self-care activities in the intervention group.

CONCLUSIONS: A clinical pharmacist-led care program in a public hospital's outpatient diabetes clinic was associated with significant improvements in reducing A1C and other secondary outcomes in a 12-month randomized controlled study.

J Manag Care Spec Pharm. 2017;23(5):573-82

Copyright $\odot 2017$, Academy of Managed Care Pharmacy. All rights reserved.

\section{What is already known about this subject}

Despite new medications and specific care for patients with type 2 diabetes, controlling glycemic parameters, blood pressure, and lipid profile, the control of diabetes remains largely insufficient. Improvements in medication adherence and self-care activities are associated with better glycemic control in patients with type 2 diabetes.

Pharmaceutical care programs, led by pharmacists in previous studies and carried out in different settings, have shown improvements in the control of diabetes.

\section{What this study adds}

This study evaluated the effect of a 12-month clinical pharmacistled care program on health care behaviors of type 2 diabetes patients in Northern Cyprus.

Because approximately $70 \%$ of the study participants were obese patients with type 2 diabetes, the pharmacist-led care program focused on weight loss management and other clinical outcomes. In an outpatient setting, the pharmacist-led program improved the outcome measures of Alc, total cholesterol, blood pressure, body mass index, and waist circumference, as well as enhanced adherence and increased participation in self-care activities.

T ype 2 diabetes and obesity are likely to be major public health problems for decades to come. These conditions are strongly linked, with the increased prevalence of diabetes associated with higher rates of obesity.1,2 A cross-sectional study of a random sample of 1,780 Cypriots found that the prevalence of diabetes was $11 \%$ and that impaired glucose tolerance was 18\% in Northern Cyprus. ${ }^{3}$ In the same study, the prevalence of obesity was $31.6 \%$. Rising rates of obesity have led to an increasing prevalence of type 2 diabetes mellitus in younger people. Weight loss is associated with improvements in blood glucose control and decreased morbidity and mortality rates in those with type 2 diabetes., ${ }^{4,5}$

Several studies have shown that lowering hemoglobin Alc (Alc) levels is associated with reduced onset or progression of microvascular complications. ${ }^{6,7}$ Treatment strategies for type 2 diabetes are complex, requiring ongoing medical care, continuing patient education, and support to prevent acute complications and reduce the risk of chronic complications. ${ }^{8,9}$ 
Pharmacists can play an important role in diabetes treatment by helping patients improve their chances of reaching therapeutic and lifestyle goals. As experts in drug therapy, drug selection, and patient education, pharmacists can be excellent additions to the multidisciplinary health care team, contributing to better care for patients. ${ }^{10,11}$ They can help patients individually or with other health professionals in designing, implementing, and monitoring special therapeutic plans to improve disease state outcomes through a process known as pharmaceutical care. ${ }^{12,13}$

Several studies have reported that pharmacist-led care programs improve glycemic control, as well as other clinical outcomes such as weight reduction, blood pressure, and lipid control in patients with diabetes. ${ }^{14-17}$ Several studies have demonstrated the clinical and economic benefits of clinical pharmacy services in hospital settings..$^{18,19}$

Medication regimens of patients with type 2 diabetes are often complex, and appropriate use of medications is important for the success of diabetes care, which is associated with a high level of self-care behavior and self-management. ${ }^{20}$ Poor adherence to diabetes treatment is common among patients and can cause severe health complications, including increased mortality. ${ }^{21}$ Responsibilities of pharmacists include the optimization of medical treatment and adherence to medications. A systematic review by Antoine et al. (2014) showed that pharmacist interventions have the potential to improve adherence to medications for type 2 diabetes in such different settings as face-toface meetings, group activity, and telephone follow-up. ${ }^{20}$

Currently in Northern Cyprus, clinical pharmacists do not provide pharmaceutical care in terms of disease state management to patients in public hospitals or outpatient settings. Instead, hospital pharmacists are primarily responsible for dispensing medications to patients. Pharmacist-led care or pharmaceutical care is a new concept in Northern Cyprus, and the best of our knowledge, there are no previous reports related to pharmaceutical care programs led by clinical pharmacists in community, hospital, or outpatient settings.

The purpose of this study is to evaluate the effect of a pharmacist-led care program in a public hospital's outpatient diabetes clinic on the clinical outcome of glycemic control, determined primarily by Alc. Secondary outcomes were the effect on blood pressure, lipid profile, body mass index (BMI), waist circumference, medication adherence, and self-care activities, for patients with type 2 diabetes over a 12-month period.

\section{Methods}

\section{Setting}

This was a randomized controlled trial conducted with 152 patients at a 186-bed public hospital's outpatient diabetes clinic in Gazimagusa, Northern Cyprus. The patients were divided into 2 groups: 75 patients in the intervention group and 77 in the usual care group. There were 2 nurses and
5 physicians (in rotation during week days) providing service to 30 patients a day at the outpatient diabetes clinic. The study was conducted between October 2013 and July 2015, with 12 months of follow-up from the initial consultation (index date). A research clinical pharmacist worked 3 hours per day during weekdays at the outpatient diabetes clinic. This study was approved by the Ethical Committee of Near East University.

\section{Sample Size}

A sample size calculation, based on published data on the variability (standard deviation $[\mathrm{SD}]=2.1 \%$ ) of Alc in patients with type 2 diabetes, indicated that to detect an absolute difference of a minimum $1 \%$ in Alc, with $\alpha=0.05$ and a power of $80 \%$, a sample size of 64 patients was needed in both the intervention and usual care groups. However, taking into account that patients could miss follow-up (15\%), it was estimated that 74 patients would be required for each group.

\section{Recruitment and Randomization}

Patients regularly attending the public hospital's outpatient diabetes clinic were eligible for recruitment if they had a diagnosis of type 2 diabetes for at least 6 months, with Alc levels $>7 \%$, and were prescribed at least 1 antidiabetic medication. Patients were excluded if they had an uncontrolled psychiatric disorder. Eligible patients who wanted to participate in the study (with oral and written consent) were randomly assigned to 1 of the 2 groups: 79 patients were in the intervention group, and 80 patients were in the usual care group. The patients attending the hospital received a record number (registration number) before meeting their physicians. Eligible patients were randomized to each group using the registration number.

\section{Description of Interventions}

After randomization, baseline data for each patient from both groups were collected by the research clinical pharmacist using questionnaires, medical reports, and the hospital's record system. Data included demographic and disease characteristics, medication regimen, fasting blood glucose, Alc, and lipid profile. Blood pressure was checked and recorded by a qualified nurse, and body weight was measured by the research clinical pharmacist during each visit for the intervention group. For the usual care group, this information was collected at baseline and at the completion of the study. Patients in both groups were also asked to complete the Morisky Green test and the Summary of the Diabetes Self-Care Activities (SDSCA) questionnaire at baseline. ${ }^{22,23}$ All laboratory and questionnaire data for the patients in the intervention group were repeated during the study period.

The usual care group met with the research clinical pharmacist at baseline and at the end of 12 months to collect laboratory and questionnaire data. Patients in the usual care group received standard care provided by the outpatient diabetes 


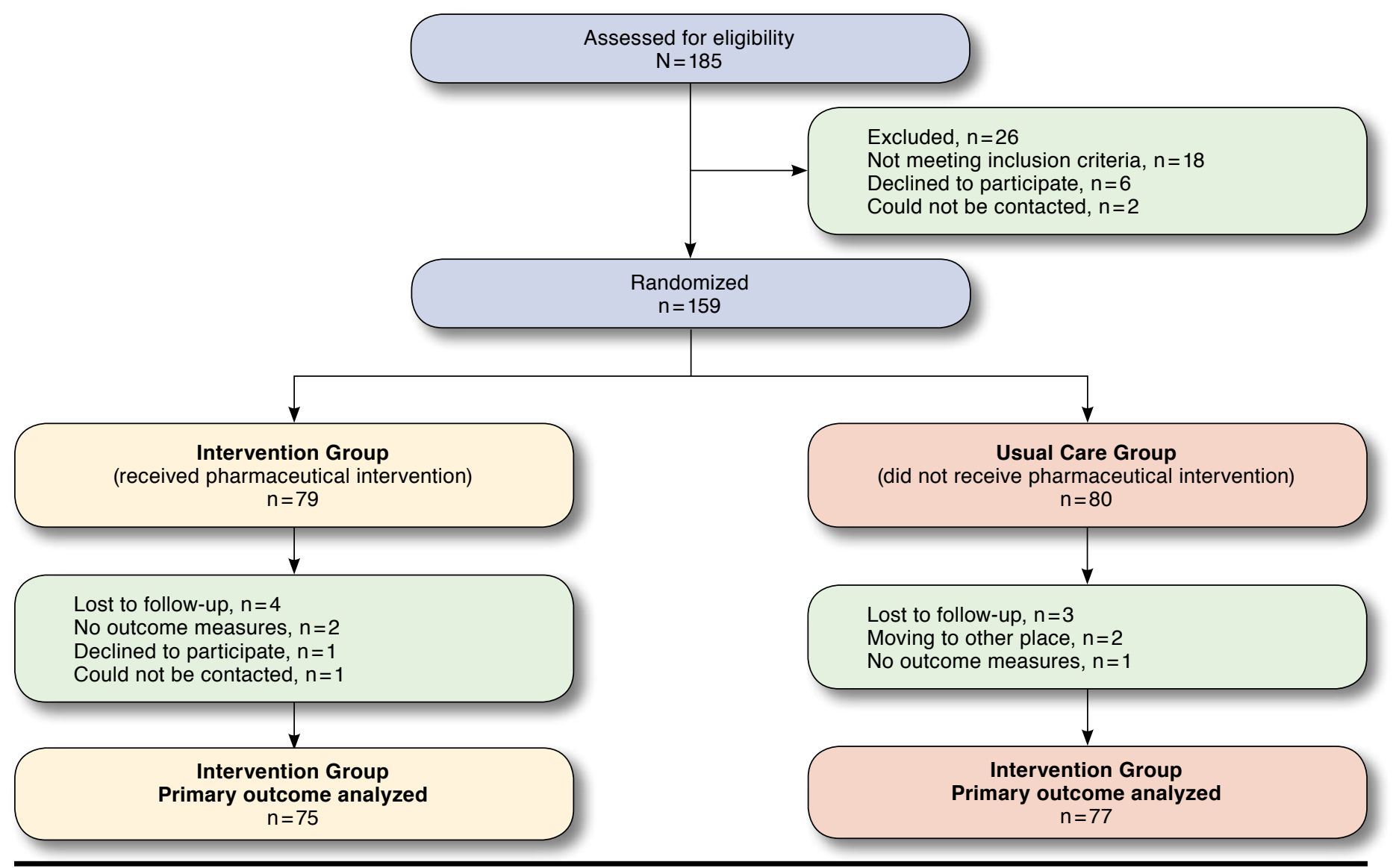

clinic. Usual care consisted of appointments with physicians every 4-8 weeks to renew prescriptions for their medicines during the study period.

Each patient in the intervention group had a scheduled meeting with the research clinical pharmacist on the same date as the appointment with the physician. The pharmacist interviewed the patient in an independent office located next to the physician's office. The intervention group met face-to-face with a pharmacist on 5 consecutive visits at 3 -month intervals and reviewed medication and treatment plans. The research pharmacist explained to each patient the importance of self-monitoring blood glucose (SMBG), a healthy diet, physical exercise, and smoking cessation and also provided a different pamphlet during each visit. The pamphlets contained information about type 2 diabetes, complications, medications, treatment goals, and self-care (e.g., SMBG, healthy diet, and exercise).

The patients were asked to bring their medications to each visit. The pharmacist's face-to-face education and discussion sessions included revision of medications, as necessary, and the sharing of diabetes knowledge, clinical goals, and self-care activities. The pharmacist discussed recommendations for changes to medication regimens (e.g., dose adjustments or drug addition/replacement) with patients and referred them to physicians when necessary. Review of the prescribed medications included the identification and resolution of medication-related problems. Nonadherence to the treatment plan, the role of the medications, and the correct use of drugs (including insulin administration methods) were also reviewed with the patients. The purpose of the pharmacist-led care program was to educate patients regarding the correct use of medication and reinforce adherence to treatment, along with developing patient knowledge of drug therapy and health conditions.

\section{SDSCA Questionnaire}

The SDSCA questionnaire (translated into Turkish and validated $^{24}$ ) is a well-documented, validated tool that measures the self-care behaviors of patients. ${ }^{23}$ It is multidimensional, and each section is answered and scored separately. The tool asks patients to recall their self-care behaviors during the previous 7 days for 5 factors: 


\section{TABLE 1 Patient Demographics and Clinical Characteristics at Baseline}

\begin{tabular}{|c|c|c|c|c|c|}
\hline \multirow{2}{*}{$\begin{array}{l}\text { Demographic and Clinical Characteristics } \\
\text { Age in years, mean } \pm S D \text { (median) }\end{array}$} & \multicolumn{2}{|c|}{ Intervention Group, $\mathrm{n}=75$} & \multicolumn{2}{|c|}{ Usual Care Group, $\mathbf{n}=77$} & \multirow{2}{*}{$\frac{P \text { Value }}{0.751}$} \\
\hline & $61.80 \pm 10.38$ & $(63.0)$ & $62.22 \pm 9.54$ & $(64.0)$ & \\
\hline \multicolumn{6}{|l|}{ Gender, n (\%) } \\
\hline Male & 17 & $(22.7)$ & 20 & $(26.0)$ & \multirow{2}{*}{0.775} \\
\hline Female & 58 & $(77.3)$ & 57 & $(74.0)$ & \\
\hline \multicolumn{6}{|l|}{ Ethnic group, n (\%) } \\
\hline Cypriots & 44 & $(58.7)$ & 45 & $(58.4)$ & \multirow{3}{*}{0.592} \\
\hline Turkish & 30 & $(40.0)$ & 32 & $(41.6)$ & \\
\hline Others & 1 & $(1.3)$ & 0 & $(0.0)$ & \\
\hline \multicolumn{6}{|l|}{ Marital status, n (\%) } \\
\hline Married & 67 & $(89.3)$ & 61 & $(80.3)$ & \multirow{2}{*}{0.185} \\
\hline Single, divorced, or separated & 8 & $(10.7)$ & 15 & $(19.7)$ & \\
\hline \multicolumn{6}{|l|}{ Education, $\mathrm{n}(\%)$} \\
\hline University & 0 & $(0.0)$ & 3 & (3.9) & \multirow{4}{*}{0.334} \\
\hline Secondary/high school & 19 & $(25.3)$ & 17 & $(22.1)$ & \\
\hline Elementary & 46 & $(61.3)$ & 49 & $(63.6)$ & \\
\hline Illiterate (or none) & 10 & (13.3) & 8 & $(10.4)$ & \\
\hline \multicolumn{6}{|l|}{ Working status, n (\%) } \\
\hline Yes & 7 & (9.3) & 14 & $(18.2)$ & \multirow{2}{*}{0.178} \\
\hline No & 68 & $(90.7)$ & 63 & $(81.8)$ & \\
\hline Smokers, n (\%) & 12 & $(16.0)$ & 14 & $(18.2)$ & 0.887 \\
\hline Drinkers, n (\%) & 6 & $(8.1)$ & 9 & $(11.7)$ & 0.643 \\
\hline Duration of diabetes in years, mean \pm SD (median) & $10.81 \pm 7.14$ & $(10.0)$ & $10.59 \pm 6.68$ & $(10.0)$ & 0.901 \\
\hline Waist circumference $(\mathrm{cm})$, mean \pm SD (median) & $109.88 \pm 12.64$ & $(110.0)$ & $108.81 \pm 9.04$ & $(109.0)$ & 0.645 \\
\hline Body mass index $\left(\mathrm{kg} / \mathrm{m}^{2}\right)$, mean $\pm \mathrm{SD}$ (median) & $33.00 \pm 4.93$ & $(34.1)$ & $32.61 \pm 4.57$ & $(31.8)$ & 0.368 \\
\hline Number of concurrent diseases, mean \pm SD (median) & $2.08 \pm 1.05$ & $(2.0)$ & $1.93 \pm 1.00$ & $(2.0)$ & 0.365 \\
\hline \multicolumn{6}{|l|}{ Comorbid conditions, $\mathrm{n}(\%)$} \\
\hline Hypertension & 60 & $(80.0)$ & 58 & $(75.3)$ & 0.619 \\
\hline Dyslipidemia & 46 & $(61.3)$ & 39 & $(50.6)$ & 0.245 \\
\hline Thyroid disorders & 16 & $(21.3)$ & 17 & $(22.1)$ & 1.000 \\
\hline Rheumatoid arthritis & 7 & $(9.3)$ & 10 & $(13.0)$ & 0.648 \\
\hline Asthma & 10 & $(13.3)$ & 9 & $(11.7)$ & 0.951 \\
\hline Heart failure & 18 & $(24.0)$ & 17 & $(22.1)$ & 0.929 \\
\hline Osteoporosis & 6 & $(8.0)$ & 5 & $(6.5)$ & 0.964 \\
\hline Psychological disorders & 13 & $(17.3)$ & 12 & $(15.6)$ & 0.943 \\
\hline Number of prescribed medications, mean \pm SD (median) & $6.42 \pm 2.11$ & $(6.0)$ & $5.83 \pm 1.84$ & $(6.0)$ & 0.030 \\
\hline $0-5$ types, $\mathrm{n}(\%)$ & 24 & $(32.0)$ & 38 & $(49.4)$ & 0.044 \\
\hline$\geq 6$ types, $\mathrm{n}(\%)$ & 51 & $(68.0)$ & 39 & $(50.6)$ & \\
\hline \multicolumn{6}{|l|}{ Antidiabetic medications, $\mathrm{n}(\%)$} \\
\hline Alpha-glucosidase inhibitor & 8 & $(10.7)$ & 4 & $(5.2)$ & 0.342 \\
\hline Metformin & 67 & $(89.3)$ & 62 & $(80.5)$ & 0.197 \\
\hline Sulphonylurea & 21 & $(28.0)$ & 20 & $(26.0)$ & 0.921 \\
\hline Insulin & 41 & $(54.7)$ & 40 & $(51.9)$ & 0.737 \\
\hline Lipid-lowering agent users, n (\%) & 43 & $(57.3)$ & 40 & $(52.0)$ & 0.722 \\
\hline Antihypertensive agent users, $\mathrm{n}(\%)$ & 60 & $(80.0)$ & 65 & $(84.4)$ & 0.316 \\
\hline
\end{tabular}

$S D=$ standard deviation

1. Diet (4 questions), for example: "How many of the last 7 days have you followed a healthy eating plan?"

2. Exercise (2 questions), for example: "During how many of the last 7 days did you participate in at least 30 minutes of physical activity?"

3. SMBG (2 questions), for example: "During how many of the last 7 days did you check your blood sugar?"
4. Foot care (2 questions), for example: "During how many of the last 7 days did you check inside your shoes?"

5. Smoking (2 questions), for example: "Have you smoked a cigarette, even 1 puff, during the last 7 days?"

\section{Adherence}

Medication adherence was assessed using the Morisky-Green test (translated into Turkish and validated) at baseline and at 


\begin{tabular}{|c|c|c|c|c|c|c|c|c|c|}
\hline \multirow[b]{2}{*}{ Outcome Measures } & \multicolumn{4}{|c|}{$\begin{array}{l}\text { Intervention Group } \\
\qquad \mathrm{n}=75\end{array}$} & \multicolumn{4}{|c|}{$\begin{array}{l}\text { Usual Care Group } \\
\qquad \mathbf{n}=77\end{array}$} & \multirow{2}{*}{\begin{tabular}{|c|} 
Between \\
Groups \\
Mean \\
Difference \\
\\
$P$ \\
Value \\
\end{tabular}} \\
\hline & $\begin{array}{c}\text { Baseline } \\
\text { Mean } \pm \text { SD } \\
(\text { Median) }\end{array}$ & $\begin{array}{c}\text { End of Study } \\
\text { Mean } \pm \text { SD } \\
\text { (Median) }\end{array}$ & $\begin{array}{c}\text { Mean } \\
\text { Difference }\end{array}$ & $\begin{array}{c}P \\
\text { Value }\end{array}$ & $\begin{array}{c}\text { Baseline } \\
\text { Mean } \pm \text { SD } \\
\text { (Median) }\end{array}$ & $\begin{array}{l}\text { End of Study } \\
\text { Mean } \pm \text { SD } \\
\text { (Median) }\end{array}$ & $\begin{array}{c}\text { Mean } \\
\text { Difference }\end{array}$ & $\begin{array}{c}P \\
\text { Value }\end{array}$ & \\
\hline Alc (\%) & $\begin{array}{c}8.29 \pm 0.89 \\
(8.2)\end{array}$ & $\begin{array}{c}7.55 \pm 0.57 \\
(7.5)\end{array}$ & -0.74 & $<0.001$ & $\begin{array}{c}8.31 \pm 0.84 \\
(8.3)\end{array}$ & $\begin{array}{c}8.26 \pm 0.74 \\
(8.2)\end{array}$ & -0.04 & 0.671 & $<0.001$ \\
\hline Systolic BP (mmHg) & $\begin{array}{c}132.27 \pm 16.07 \\
(130)\end{array}$ & $\begin{array}{c}125.47 \pm 13.68 \\
(120)\end{array}$ & -6.80 & 0.002 & $\begin{array}{c}132.08 \pm 19.25 \\
(130)\end{array}$ & $\begin{array}{c}133.51 \pm 14.30 \\
(130)\end{array}$ & 1.42 & 0.415 & 0.011 \\
\hline Diastolic BP (mmHg) & $\begin{array}{c}81.18 \pm 8.52 \\
(80)\end{array}$ & $\begin{array}{c}78.80 \pm 8.21 \\
(80)\end{array}$ & -2.38 & 0.035 & $\begin{array}{c}82.46 \pm 11.82 \\
(80)\end{array}$ & $\begin{array}{c}83.50 \pm 7.90 \\
(80)\end{array}$ & 1.03 & 0.558 & 0.042 \\
\hline Fasting blood glucose (mg/dL) & $\begin{array}{c}214.96 \pm 59.29 \\
(215)\end{array}$ & $\begin{array}{c}184.68 \pm 43.68 \\
(180)\end{array}$ & -30.28 & $<0.001$ & $\begin{array}{c}218.13 \pm 42.08 \\
(210)\end{array}$ & $\begin{array}{c}195.48 \pm 65.91 \\
(185)\end{array}$ & -22.54 & 0.001 & 0.410 \\
\hline Total cholesterol (mg/dL) & $\begin{array}{c}197.37 \pm 42.15 \\
(190)\end{array}$ & $\begin{array}{c}192.59 \pm 31.81 \\
(193)\end{array}$ & -4.78 & 0.149 & $\begin{array}{c}201.92 \pm 36.10 \\
(196)\end{array}$ & $\begin{array}{c}203.87 \pm 34.39 \\
(203)\end{array}$ & 1.94 & 0.178 & 0.040 \\
\hline Triglyceride (mg/dL) & $\begin{array}{c}162.60 \pm 75.5 \\
(145)\end{array}$ & $\begin{array}{c}165.67 \pm 73.61 \\
(155)\end{array}$ & 3.06 & 0.052 & $\begin{array}{c}158.48 \pm 68.11 \\
(155)\end{array}$ & $\begin{array}{c}162.78 \pm 65.36 \\
(153)\end{array}$ & 3.29 & 0.025 & 0.896 \\
\hline LDL-C (mg/dL) & $\begin{array}{c}122.13 \pm 38.16 \\
(113)\end{array}$ & $\begin{array}{c}116.93 \pm 26.86 \\
(112)\end{array}$ & -5.20 & 0.119 & $\begin{array}{c}124.22 \pm 32.16 \\
(118)\end{array}$ & $\begin{array}{c}125.62 \pm 30.80 \\
(120)\end{array}$ & 1.40 & 0.285 & 0.063 \\
\hline HDL-C (mg/dL) & $\begin{array}{c}42.72 \pm 7.80 \\
(41)\end{array}$ & $\begin{array}{c}42.50 \pm 7.48 \\
(42)\end{array}$ & -0.20 & 0.014 & $\begin{array}{c}45.80 \pm 8.66 \\
(46)\end{array}$ & $\begin{array}{c}45.59 \pm 7.87 \\
(46)\end{array}$ & -0.20 & 0.681 & 0.331 \\
\hline BMI $\left(\mathrm{kg} / \mathrm{m}^{2}\right)$ & $\begin{array}{c}33.00 \pm 4.93 \\
(34.10)\end{array}$ & $\begin{array}{c}31.728 \pm 4.31 \\
(32.40)\end{array}$ & -1.24 & $<0.001$ & $\begin{array}{c}32.61 \pm 4.57 \\
\quad(31.80)\end{array}$ & $\begin{array}{c}33.019 \pm 4.61 \\
(32.30)\end{array}$ & 0.40 & 0.016 & $<0.001$ \\
\hline Waist circumference $(\mathrm{cm})$ & $\begin{array}{c}109.88 \pm 12.64 \\
(110)\end{array}$ & $\begin{array}{c}107.93 \pm 11.26 \\
(108)\end{array}$ & -1.94 & $<0.001$ & $\begin{array}{c}108.81 \pm 9.04 \\
(109)\end{array}$ & $\begin{array}{c}109.45 \pm 8.98 \\
(110)\end{array}$ & 0.64 & 0.008 & $<0.001$ \\
\hline
\end{tabular}

Alc=hemoglobin Alc; BMI=body mass index; BP=blood pressure; HDL-C=high-density cholesterol; LDL-C=low-density cholesterol; SD = standard deviation.

the 12-month follow-up. ${ }^{22,25}$ This test consists of 4 questions: (1) "Have you ever (do you ever) forgotten to take your medicine?"; (2) "Are you careless at times about taking your medicine?"; (3) "When you feel better, do you sometimes stop taking your medicine?"; and (4) "Sometimes, if you feel worse when you take your medicine, do you stop taking your medicine?". Patients were considered adherent to pharmacotherapy if they answered "no" to all 4 questions. If a patient answered "yes" to any question, the patient was considered nonadherent.

\section{Outcome Measures}

The main outcome measure was change in Alc. Secondary outcome measures were changes in fasting blood glucose, blood pressure, lipid profile, BMI, waist circumference, self-reported self-care activities, and medication adherence scores, all of which were measured at baseline and up to 12 months.

The effects of the pharmacist-led care program on clinical outcomes and pharmacotherapy adherence were determined by comparing the baseline values with the final results for the intervention and the usual care groups. The goals for patients with diabetes were blood pressure $<140 / 90 \mathrm{mmHg}$, fasting glucose $<80-130 \mathrm{mg} / \mathrm{dL}$, Alc $<7 \%$, triglycerides $<150 \mathrm{mg} / \mathrm{dL}$, low-density lipoprotein cholesterol (LDL-C) $<100 \mathrm{mg} / \mathrm{dL}$, and high-density lipoprotein cholesterol (HDL-C) $>40 \mathrm{mg} / \mathrm{dL}$ (for women, $>50 \mathrm{mg} / \mathrm{dL}$ ).

\section{Statistical Analysis}

Data collected at baseline and at the end of 12 months were assessed using SPSS software, version 16 (SPSS Inc., Chicago, IL). The $\chi^{2}$ or Fisher's exact tests were used to compare categorical variables. As normality test results for continuous variables showed non-normal distributions, the Mann-Whitney U test was used to compare mean differences between the intervention and usual care groups. The Wilcoxon test was used to determine differences in characteristics between baseline and at the end of 12 months within groups.

\section{Results}

During the study period, 159 eligible patients attending an outpatient diabetes clinic in a public hospital were asked to participate in this study. Of those, 75 of 79 patients in the intervention group and 77 of 80 patients in the usual care group completed the study (Figure 1). Patient characteristics are shown in Table 1.

There were no significant differences $(P>0.05)$ in patient characteristics between the groups except for the number of prescribed medicines (6.42 for intervention vs. 5.83 for usual care; $P=0.03$ ). In total, $70 \%$ of the intervention and $74 \%$ of the usual care patients were obese at baseline. At baseline assessment, Alc, fasting blood glucose, systolic (SBP) and diastolic (DBP) blood pressure, and lipid parameters were similar between the groups (Table 2). 
TABLE 3 Adherence Rate of Patients According to Morisky-Green Test

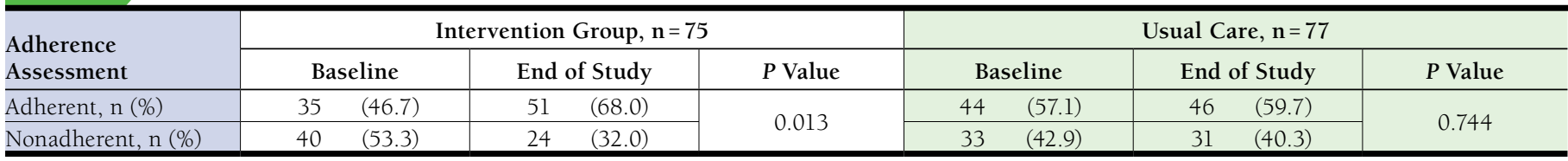

\section{A1c and Fasting Blood Glucose}

The intervention patients achieved a greater reduction in Alc values than the usual care patients $(-0.74 \%$ vs. $-0.04 \%$; $P<0.001)$ at the end of the 12 -month study period. The percentage of patients who reached the American Diabetes Association (ADA) goal of Alc $<7 \%$ was significantly higher in the intervention group (16\%) than in the usual care group (0\%) at the end of the 12-month study period $(P=0.001){ }^{8}$

Both groups showed significant reductions in fasting blood glucose between baseline and the end of the study period (intervention group: $-30.28 \mathrm{mg} / \mathrm{dL}, P<0.001$ vs. usual care group: $-22.54 \mathrm{mg} / \mathrm{dL}, P=0.001$; Table 2 ). However, the reduction in the intervention arm was not significantly larger than that in the usual care arm (net difference: $P=0.410$ ).

\section{Systolic and Diastolic Blood Pressure}

Comparing the intervention group with the usual care group, there were significant decreases in SBP $(P=0.01)$ and DBP $(P=0.04)$ at the end of the trial. The percentage of patients who reached the ADA goals for SBP and DBP $(<140 / 90 \mathrm{mmHg})$ was significantly higher in the intervention group (SBP: 78.7\%, DBP: 84.3\%) than in the usual care group (SBP: $55.8 \%$, DBP: $64.9 \%$ ) at the end of the 12-month period (SBP: $P=0.005$, DBP: $P=0.007$ ). ${ }^{8}$

\section{Lipid Profile}

A significant decrease in total cholesterol was achieved in the intervention group versus the usual care group $(-4.78 \mathrm{mg} / \mathrm{dL}$ vs. $+1.94 \mathrm{mg} / \mathrm{dL}, P=0.04)$. No significant differences were found in LDL-C, HDL-C, or triglyceride values between the groups $(P=0.063,0.331$, and 0.896 , respectively).

\section{Body Mass Index and Waist Circumference}

Significant reductions in BMI $\left(-1.24 \mathrm{~kg} / \mathrm{m}^{2}\right.$ vs. $+0.4 \mathrm{~kg} / \mathrm{m}^{2}$, $P<0.001)$ and waist circumference $(-1.94 \mathrm{~cm}$ vs. $+0.64 \mathrm{~cm}$, $P<0.001)$ were observed in the intervention group versus the usual care group at the end of the 12-month study period.

\section{Adherence}

According to the Morisky-Green test, at baseline 53\% of intervention and $43 \%$ of usual care patients were nonadherent (Table 3). During the study period, the intervention group showed a significant increase $(P=0.013)$ in pharmacotherapy adherence, whereas the usual care group showed no significant $(P=0.744)$ changes compared with the baseline values.

\section{Self-Care Activities}

Patients in the intervention group achieved significant improvements in their total diet score $(+0.51$ day/week, $P<0.001)$, total SMBG score $(+3.92$ day/week, $P<0.001)$, and total foot care score $(+1.60$ day/week, $P<0.001)$ versus the usual care patients (Table 4). Patients in the usual care group did not achieve any significant improvements in any of the 5 domains. Each total score in Table 4 is the mean value of the answers to the questions included in the 5 domains.

\section{Discussion}

To the best of our knowledge, this is the first study to determine the effect of a clinical pharmacy service on the outcomes of patients with type 2 diabetes in Northern Cyprus. The role of clinical pharmacy services and pharmacist-led care are new concepts in Northern Cyprus, and no study has measured the effects of pharmacist services on patients with diabetes. During the study period, a clinical pharmacist optimized pharmacotherapy, discussing changes in medication regimens (e.g., dose adjustments, drug addition or replacement) with patients and physicians as necessary and providing individualized selfmanagement education and adherence support to patients to help them achieve their glycemic control goals. During the revision of prescribed medications, the correct use of drugs, proper dosage, and possible side effects were also reviewed with the patients. For patients with high, uncontrolled blood glucose levels, a more intensive treatment with more stringent SMBG were discussed with their physicians. The clinical pharmacist emphasized the importance of lifestyle changes, such as a healthy diet, regular physical activity, SMBG, and smoking cessation with the intervention patients during the study period.

We observed a significant reduction in mean Alc levels, from $8.29 \%$ to $7.55 \%(P<0.001)$ in the intervention group. The proportion of patients who had reached the Alc goal of $<7 \%$ increased from $0 \%$ at baseline to $16 \%$ at the end of the study in the intervention group. Pharmaceutical care programs in other studies carried out in different settings have also reported reductions in Alc values. ${ }^{26-29} \mathrm{~A}$ recent review by Pousinho et al. (2016) showed a reduction in Alc between $0.18 \%$ and $2.1 \%$ in different health care facilities. ${ }^{30}$ According to the United Kingdom Prospective Diabetes Study, each 1\% reduction in Alc levels reduces the risk of death related to diabetes by $21 \%$, the risk of myocardial infarction by $14 \%$, and the risk of 
Effect of a Pharmacist-Led Program on Improving Outcomes in Patients with

Type 2 Diabetes Mellitus from Northern Cyprus: A Randomized Controlled Trial

TABLE 4 Change in Self-Care Activity Scores

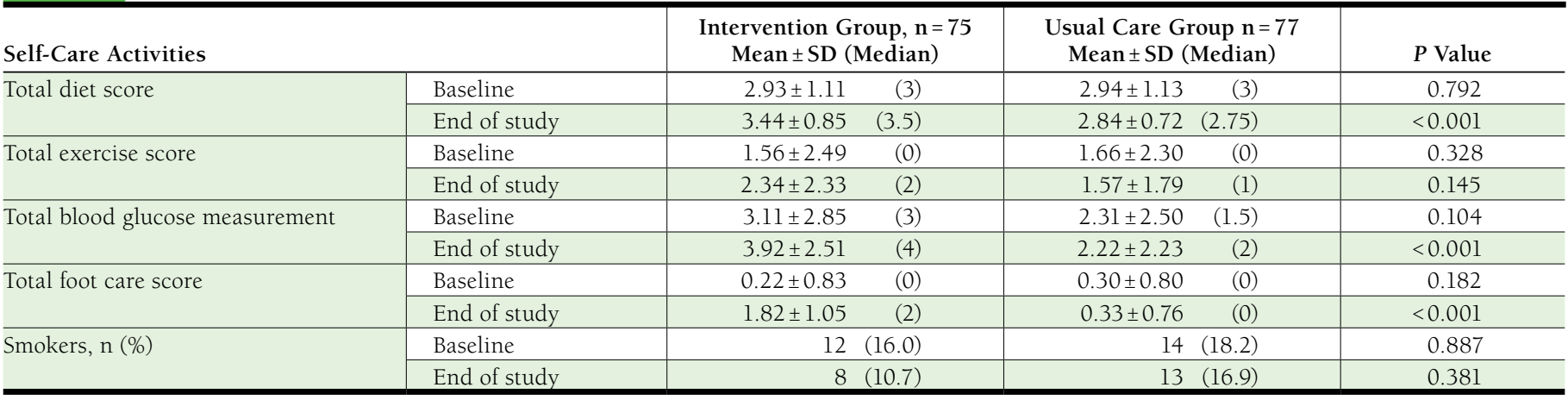

microvascular complications by $37 \% .{ }^{6}$ The reduction in Alc levels $(0.74 \%)$ in this study may be beneficial because it suggests that a clinical pharmacist can significantly contribute to improved Alc values, which may reduce clinical complications.

Because there were several parts to the intervention process, it is difficult to determine which element contributed most to improved glycemic control. The intervention process consisted of pharmacotherapy optimization, education about diabetes and related complications, self-management support, and scheduled visits, which led to an intense patient-pharmacist relationship. However, we also demonstrated that the pharmacist-led care program increased patient adherence to the diabetes medication regimen and diabetes self-care activities. Thus, these lifestyle changes may have also improved glycemic control.

Despite a greater decrease in fasting blood glucose in the intervention group than in the usual care group $(-30.28 \mathrm{mg} / \mathrm{dL}$ vs. $-22.54 \mathrm{mg} / \mathrm{dL})$, the difference was not significant $(P=0.410)$. In Mehuys et al. (2011), ${ }^{31}$ the control $(-8.1 \mathrm{mg} / \mathrm{dL})$ and intervention groups $(-14.1 \mathrm{mg} / \mathrm{dL})$ showed significant reductions in fasting blood glucose between baseline and the end of the study-again, the difference between the groups was not significant. In the Fremantle Diabetes study (2005), a smaller but statistically significant reduction $(<15 \mathrm{mg} / \mathrm{dL})$ was observed in fasting blood glucose levels in patients with diabetes. ${ }^{32}$ Mourão et al. (2013) found a significant $21.4 \mathrm{mg} / \mathrm{dL}$ decrease in the intervention group versus control patients. ${ }^{26}$ The differences in our results may have been because of our small sample size or some acute disturbances (e.g., stress, dietary habits, exercise, or smoking) that might have affected the fasting plasma glucose levels of the study subjects.

In our study, the intervention group showed significant decreases in SBP $(P=0.011)$ and DBP $(P=0.042)$ compared with the usual care group. An important finding was that significantly more patients in the intervention group (79\% for SBP and $84 \%$ for DBP) than in the usual care group (56\% for SBP and $65 \%$ for DBP) achieved the ADA target goals $\left(<140 / 90 \mathrm{mmHg}\right.$ ) for SBP and DBP (data not shown). ${ }^{8}$ Other studies have shown heterogeneous results for any effect of pharmaceutical care programs on blood pressure control. A 12-month pharmaceutical care program showed significant reductions $(P<0.001)$ in SBP and DBP. ${ }^{28}$ Jarab et al. (2012) reported small but significant improvements in SBP $(P=0.035)$ and DBP $(P=0.026)$ over a 6 -month follow-up study. ${ }^{27}$ Mourão et al. reported no significant reduction in DBP $(P=0.809)$ but did see a significant reduction in SBP $(P=0.013) .{ }^{26}$ The results of our study are consistent with these earlier studies, showing that pharmaceutical care significantly improved SBP and DBP. These results might have been a result of education (about diabetes and its complications), improvements in lifestyle behaviors, and/or medication adherence.

Study results also indicate that although the pharmacist-led care program had a positive influence on lipid control, only total cholesterol levels changed significantly $(P=0.04)$. The (net difference) reduction in LDL-C levels was close to significant $(P=0.063)$. These results are similar to the findings of other studies. Nola et al. (2000) did not find a significant reduction in total cholesterol, triglycerides, or LDL-C levels compared with controls in a 6-month community pharmacy setting. ${ }^{33}$ Kelly and Rodgers (2000) reported nonsignificant differences $(P=0.21)$ between baseline and follow-up LDL-C levels with a mean duration of 7 months. ${ }^{34} \mathrm{~A}$ pharmacy care program reported by Lee et al. (2006) found significant reductions $(P=0.01)$ in LDL-C in the first 8 months, but LDL-C was not reduced further from 9 to 14 months in the continued pharmacy care group and was not significantly different $(P=0.85)$ between study groups. ${ }^{35}$ In our study, education about lifestyle behaviors, particularly related to food intake, may have influenced lipid control positively.

According to these diverse results from different studies, the effectiveness of pharmaceutical care in the control of blood glucose, blood pressure, and lipid levels seems to depend on patient behaviors and characteristics, as well as the study 
design, intervention period, and the different features of the health system where the study was conducted.

Significant reductions in BMI $\left(-1.24 \mathrm{~kg} / \mathrm{m}^{2}\right.$ vs. $+0.4 \mathrm{~kg} / \mathrm{m}^{2}$, $P<0.001)$ and waist circumference $(-1.94 \mathrm{~cm}$ vs. $+0.64 \mathrm{~cm}$, $P<0.001$ ) were observed in the intervention group versus the usual care group at the end of 12 months. There is variability among published results concerning the effectiveness of pharmaceutical care on reducing BMI and waist circumference in different settings. In a 3-month study in Turkey, a significant reduction $\left(-0.4 \mathrm{~kg} / \mathrm{m}^{2}\right)$ was achieved in BMI values. ${ }^{36}$ In the Fremantle Diabetes Study, the pharmaceutical care program reduced BMI from $30.0 \mathrm{~kg} / \mathrm{m}^{2}$ to $29.4 \mathrm{~kg} / \mathrm{m}^{2}$ over 12 months. ${ }^{32}$ In a study by Al Mazroui et al. (2009) in the United Arab Emirates, a greater reduction in BMI $\left(-1.05 \mathrm{~kg} / \mathrm{m}^{2}\right)$ was reported at the end of 12 months, but from a lower baseline value $\left(28.34 \mathrm{~kg} / \mathrm{m}^{2}\right){ }^{28}$ In a 36 -month study in Brazil by Obreli-Neto et al. (2011), significant reductions in BMI $\left(-0.1 \mathrm{~kg} / \mathrm{m}^{2}\right)$ and abdominal circumference $(-0.6 \mathrm{~cm})$ were achieved. ${ }^{37}$ Because diabetes and obesity are independently associated with poor cardiovascular outcomes and increased mortality rates, ${ }^{4,38}$ maintenance of a healthy body weight was an important component of the diabetes management program in our study.

Our results, consistent with earlier studies, show that pharmacist-led care improved medication adherence over a 12 -month period. This care focused primarily on a patient's individual situation. During the study period, the consultations with the pharmacist led to the development of a strong patient-pharmacist professional relationship. These consultations may have increased the confidence of patients and thus contributed to improved medication adherence. The often complex medication regimens of patients with type 2 diabetes play an important role in the success of diabetes care, and this is associated with self-care behavior and self-management. Poor adherence to diabetes treatment is common among patients and can cause severe health complications, with an increase in mortality rates. ${ }^{20}$ A systematic review showed that pharmacist interventions might potentially improve medication adherence in patients with type 2 diabetes. ${ }^{21}$ In several studies, high-quality communication between patients and health care providers, as well as patient education sessions by pharmacists, resulted in improvements in medication adherence in diabetes. ${ }^{39,40}$ It is well documented that poor medication adherence among patients is associated with increased hospitalizations and emergency department visits and often leads to poor glycemic control. ${ }^{41}$

Significant improvements were observed in self-care activities such as diet, SMBG, and foot care. This study showed no significant improvement in the exercise or smoking behavior domains. Although there was an increase in the number of days per week that intervention patients did exercise, the difference was not significant compared with usual care patients. Earlier studies have reported similar findings. Jarab et al. reported in an randomized controlled trial that a clinical pharmacist effectively improved dietary habits and SMBG but not smoking cessation. ${ }^{27}$ Mehuys et al. reported significant improvements in the domains of specific diet and foot care in a 6-month community pharmacy setting. ${ }^{31}$ However, Clifford et al. (2005) found no change in either exercise participation during the study or in the intensity of the exercise involved in regular activity. ${ }^{32}$ The significant improvements in self-care activities in our study might be attributable to the intense education provided by the pharmacist about nonpharmacological treatment and the availability of a different pamphlet (e.g., containing suggestions about a healthy diet, SMBG, and foot care) at each visit.

\section{Limitations}

This study has some limitations. First, it was conducted at a single center with a small number of participants and over a period of 12 months, so our patients may not have been completely representative of the general diabetic population. The patient numbers in this study may have limited our ability to detect improvements in some outcomes. Some cross-contamination between participants in the usual care and intervention groups might also have occurred because the participants were attending the same outpatient diabetes clinic, which was located in a small community where many residents have close relationships. The Hawthorne effect, which might have influenced patient behaviors, also could not be excluded.42 Moreover, because blinding the pharmacist's activities was not possible, other health care providers were aware of these activities, so there might have also been an increase in overall care and attention by those health care providers. Furthermore, it is likely not possible to generalize these results to all pharmacists because the participating pharmacist was well trained in diabetes programs as a clinical pharmacist and specialized in pharmaceutical care issues. Pharmacists without special training in pharmaceutical care of diabetes may provide more limited benefits to patients.

\section{Conclusions}

A pharmacist-led intervention can help provide care to patients with type 2 diabetes in an outpatient setting, improving Alc, total cholesterol, blood pressure levels, BMI, and adherence to medication regimens. In this study, a clinical pharmacist, who was a qualified diabetes educator, used his expertise to help patients, providing knowledge about disease management, encouraging them to reach therapeutic and lifestyle goals, and supporting them in adhering to their medication regimens. Study results suggest that well-trained clinical pharmacists can be involved in diabetes care to help patients more effectively control their disease. This study's results can be extended 
to other hospitals in Cyprus by implementing clinical pharmacy services and providing pharmaceutical care for chronic diseases such as diabetes.

\section{Authors}

EYLEM ILKTAC KORCEGEZ, MSc, PhD Candidate, Department of Clinical Pharmacy, Near East University Faculty of Pharmacy, Nicosia, Northern Cyprus; MESUT SANCAR, PhD, Department of Clinical Pharmacy, Marmara University Faculty of Pharmacy, Istanbul, Turkey; and KUTAY DEMIRKAN, PharmD, Department of Clinical Pharmacy, Hacettepe University Faculty of Pharmacy, Ankara, Turkey.

AUTHOR CORRESPONDENCE: Eylem Ilktac Korcegez, MSc, PhD Candidate, Department of Clinical Pharmacy, Near East University Faculty of Pharmacy, Yakın Doğu Blv, Nicosia, Northern Cyprus. Tel.: +90 39236531 30; E-mail: eylemil@hotmail.com.

\section{DISCLOSURES}

This study was conducted as a PhD thesis by Korcegez under the supervision of Sancar for the clinical pharmacy program at Near East University, Health Sciences Institute, Northern Cyprus, and received no external funding. The authors have no potential conflicts of interest to report.

Study concept and design were contributed by Korcegez, with assistance from Sancar and Demirkan. Korcegez took the lead in data collection, and data interpretation was performed by Korcegez, along with Sancar and Korcegez. The manuscript was written and revised by Korcegez, along with Sancar, and with assistance from Demirkan.

\section{REFERENCES}

1. Chen L, Magliano DJ, Zimmet PZ. The worldwide epidemiology of type 2 diabetes mellitus-present and future perspectives. Nat Rev Endocrinol. 2011;8(4):228-36

2. Smith KB, Smith MS. Obesity statistics. Prim Care. 2016;43(1):121-35.

3. North Cyprus Ministry of Health. The prevalence of diabetes in North Cyprus. Available at: http://www.diyabetdernegi.com/yayin/diyabet_dernegi. pdf. Accessed March 29, 2017.

4. Flegal KM, Kit BK, Orpana H, Graubard BI. Association of all cause mortality with overweight and obesity using standard body mass index categories: a systematic review and meta-analysis. JAMA. 2013;309(1):71-82.

5. Tobias DK, Pan A, Jackson CL, et al. Body-mass index and mortality among adults with incident type 2 diabetes. N Engl J Med. 2014;16;370(3); 233-44. Available at: http://www.ncbi.nlm.nih.gov/pmc/articles/ PMC3966911/. Accessed March 14, 2017.

6. Stratton IM, Adler AI, Neil HA, et al. Association of glycaemia with macrovascular and microvascular complications of type 2 diabetes (UKPDS 35): prospective observational study. BMJ. 2000; 321(7258):405-12. Available at: http:// www.ncbi.nlm.nih.gov/pmc/articles/PMC27454/. Accessed March 14, 2017.

7. Singh A, Donnino R, Weintraub H, Schwartzbard A. Effect of strict glycemic control in patients with diabetes mellitus on frequency of macrovascular events. Am J Cardiol. 2013;1;112(7):1033-38.

8. American Diabetes Association. Standards of medical care in diabetes2015. Diabetes Care. 2015;38(Suppl 1):S1-S94. Available at: http://care.diabetesjournals.org/content/suppl/2014/12/23/38.Supplement_1.DC1/January_ Supplement_Combined_Final.6-99.pdf. Accessed March 14, 2017.
9. Norris SL, Lau J, Smith SJ. Self-management educations for adults with type 2 diabetes: a meta-analysis of the effect on glycemic control. Diabetes Care. 2002;25(7):1159-71. Available at: http://care.diabetesjournals.org/content/25/7/1159.long. Accessed March 14, 2017.

10. Wubben D, Vivian E. Effects of pharmacist outpatient interventions on adults with diabetes mellitus: a systematic review. Pharmacotherapy. 2008;28(4):421-36.

11. Toklu HZ, Hussain A. The changing face of pharmacy practice and the need for a new model of pharmacy education. J Young Pharm. 2013;5(2):38-40. Available at: http://www.ncbi.nlm.nih.gov/pmc/articles/PMC3758081/. Accessed March 14, 2017.

12. Hepler C, Strand L. Opportunities and responsibilities in pharmaceutical care. Am J Hosp Pharm. 1990;47(3):533-43.

13. Strand LM. 1997 Remington Lecture. Re-visioning the profession. J Am Pharm Assoc (Wash). 1997;37(4):474-48.

14. Machado M, Bajcar J, Guzzo GC, Einarson TR. Sensitivity of patient outcomes to pharmacist interventions. Part I: systematic review and metaanalysis in diabetes management. Ann Pharmacother. 2007;41:1569-82.

15. Fornos JA, Andres NF, Andres JC, Guerra MM, Egea B. A pharmacotherapy follow-up programme in patients with Type-2 diabetes in community pharmacies in Spain. Pharm World Sci. 2006;28(2):65-72.

16. Botomino A, Bruppacher R, Krahenbuehl S, Hersberger KE. Change of body weight and lifestyle of persons at risk for diabetes after screening and counselling in pharmacies. Pharm World Sci. 2007;30(3):222-26

17. Planas LG, Crosby KM, Mitchell KD, Farmer KC. Evaluation of hypertension medication therapy management programmes in patients with diabetes mellitus. J Am Pharm Assoc (2003). 2009;49(2):164-70.

18. Forjuoh SN, Huber C, Bolin JN, et al. Provision of counseling on diabetes self-management: are there any age disparities? Patient Educ Couns. 2011;85(2):133-39. Available at: http://www.ncbi.nlm.nih.gov/pmc/articles/ PMC3021766/. Accessed March 14, 2017.

19. Borges AP, Guidoni CM, Ferreira LD, de Freitas O, Pereira LR. The pharmaceutical care of patients with Type 2 diabetes mellitus. Pharm World Sci. 2010;32(6):730-36.

20. Antoine SL, Pieper D, Mathes T, Eikermann M. Improving the adherence of type 2 diabetes mellitus patients with pharmacy care: a systematic review of randomized controlled trials. BMC Endocr Disord. 2014;7;14:53. Available at: http://www.ncbi.nlm.nih.gov/pmc/articles/PMC4105396/. Accessed March 14, 2017.

21. Ho PM, Rumsfeld JS, Masoudi FA, et al. Effect of medication nonadherence on hospitalization and mortality among patients with diabetes mellitus. Arch Intern Med. 2006;25;166(17):1836-41. Available at: http://archinte.jamanetwork.com/article. aspx?articleid=410956. Accessed March 14, 2017.

22. Morisky DE, Green LW, Levine DM. Concurrent and predictive validity of a self-reported measure of medication adherence. Med Care. 1986;24(1):67-74.

23. Toobert DJ, Hampson SE, Glasgow RE. The summary of diabetes selfcare activities measure: results from 7 studies and a revised scale. Diabetes Care. 2000;23(7):943-50. Available at: http://care.diabetesjournals.org/content/23/7/943.long. Accessed March 14, 2017

24. Kav S, Akman A, Dogan N, Tarakci Z, Bulut Y, Hanoglu Z. Turkish validity and reliability of the summary of diabetes self-care activities measure for patients with type 2 diabetes mellitus. J Clin Nurs. 2010;19(19-20):2933-35.

25. Yllmaz S, Buzlu S. Side effects of medications and adherence to medication in patients using antipsychotics [in Turkish]. Florence Nightingale Hemşirelik Dergisi. 2011;20:93-103. Avaliable at: http://dergipark.gov.tr/iufnhy/issue/9007/112176. Accessed March 29, 2017.

26. Mourão AO, Ferreira WR, Martins MA, et al. Pharmaceutical care program for type 2 diabetes patients in Brazil: a randomised controlled trial. Int J Clin Pharm. 2013;35(1):79-86. 
27. Jarab AS, Alqudah SG, Mukattash TL, Shattat G, Al-Qirim T. Randomized controlled trial of clinical pharmacy management of patients with type 2 diabetes in an outpatient diabetes clinic in Jordan. J Manag Care Pharm. 2012;187(7):516-26. Available at: http://www.jmcp.org/doi/ pdf/10.18553/jmcp.2012.18.7.516.

28. Al Mazroui NR, Kamal MM, Ghabash NM, Yacout TA, Kole PL, McElnay JC. Influence of pharmaceutical care on health outcomes in patients with type 2 diabetes mellitus. Br J Clin Pharmacol. 2009;67(5):547-57.

29. Choe HM, Mitrovich S, Dubay D, Hayward RA, Krein SL, Vijan S. Proactive case management of high-risk patients with Type 2 diabetes mellitus by a clinical pharmacist: a randomized controlled trial. Am J Manag Care. 2005;11(4):253-60. Available at: http://www.ajmc.com/journals/issue/2005/ 2005-04-voll1-n4/Apr05-2017p0253-0260/. Accessed March 14, 2017.

30. Pousinho S, Morgado M, Falcão A, Alves G. Pharmacist interventions in the management of type 2 diabetes mellitus: a systematic review of randomized controlled trials. J Manag Care Spec Pharm. 2016;22(5):493-515. Available at: http://www.jmcp.org/doi/pdf/10.18553/jmcp.2016.22.5.493.

31. Mehuys E, Van Bortel L, De Bolle L, Van Tongelen I, Annemans L, Remon JP, et al. Effectiveness of a community pharmacist intervention in diabetes care: a randomized controlled trial. J Clin Pharm Ther. 2011;36(5):602-13.

32. Clifford RM, Davis WA, Batty KT, Davis TM. Effect of a pharmaceutical care program on vascular risk factors in Type 2 diabetes: the Fremantle Diabetes Study. Diabetes Care. 2005;28(4):771-76. Available at: http://care. diabetesjournals.org/content/28/4/771.long. Accessed March 14, 2017.

33. Nola KM, Gourley DR, Portner TS, Gourley GK, Solomon DK, Elam M, et al. Clinical and humanistic outcomes of a lipid management program in the community pharmacy setting. J Am Pharm Assoc (Wash). 2000;40(2):166-73.

34. Kelly C, Rodgers P. Implementation and evaluation of a pharmacistmanaged diabetes service. J Manag Care Pharm. 2000;6(6):488-93. Available at: http://www.jmcp.org/doi/abs/10.18553/jmcp.2000.6.6.488.
35. Lee JK, Grace KA, Taylor AJ. Effect of a pharmacy care program on medication adherence and persistence, blood pressure, and low-density lipoprotein cholesterol: a randomized controlled trial. JAMA. 2006; 296(21):2563-71. Available at: http://jama.jamanetwork.com/article. aspx?articleid=204402. Accessed March 14, 2017.

36. Turnacilar M, Sancar M, Apikoglu-Rabus S, Hursitoglu M, Izzettin FV. Improvement of diabetes indices of care by a short pharmaceutical care program. Pharm World Sci. 2009;31(6):689-95.

37. Obreli-Neto PR, Guidoni CM, de Oliveira Baldoni A, et al. Effect of a 36-month pharmaceutical care program on pharmacotherapy adherence in elderly diabetic and hypertensive patients. Int J Clin Pharm. 2011;33(4):642-49.

38. Flint AJ, Rexrode KM, Hu FB, et al. Body mass index, waist circumference, and risk of coronary heart disease: a prospective study among men and women. Obes Res Clin Pract. 2010;4(3):e171-e181. Available at: http://www. ncbi.nlm.nih.gov/pmc/articles/PMC2992336/. Accessed March 14, 2017.

39. Jin J, Sklar GE, Min Sen Oh V, Chuen Li S. Factors affecting therapeutic compliance: a review from the patient's perspective. Ther Clin Risk Manag. 2008;4(1):269-86. Available at: http://www.ncbi.nlm.nih.gov/pmc/articles/ PMC2503662\%. Accessed March 14, 2017.

40. Lindenmeyer A, Hearnshaw H, Vermeire E, Van Royen P, Wens J, Biot Y. Interventions to improve adherence to medication in people with type 2 diabetes mellitus: a review of the literature on the role of pharmacists. J Clin Pharm Ther. 2006;31(5):409-19. Available at: http://onlinelibrary.wiley. com/doi/10.1111/j.1365-2710.2006.00759.x/epdf. Accessed March 14, 2017.

41. Wong ES, Bryson CL, Hebert PL, Liu CF Estimating the impact of oral diabetes medication adherence on medical costs in VA. Ann Pharmacother. 2014;20;48(8):978-85.

42. McCarney R, Warner J, Iliffe S, van Haselen R, Griffin M, Fisher P. The Hawthorne effect: a randomised, controlled trial. BMC Med Res Methodol. 2007;3;7:30. Available at: http://www.ncbi.nlm.nih.gov/pmc/articles/ PMC1936999/pdf/1471-2288-7-30.pdf. Accessed March 14, 2017. 